Original Article

\title{
ULTRASOUND ASSISTED GREEN SYNTHESIS OF 2-FURAN-2-YL-4H-CHROMEN-4-ONES FROM CHALCONES
}

\author{
GOPAL K. KAKADE1, SURESH G. VEDPATHAK ${ }^{2}$ \\ ${ }^{1}$ Department of Chemistry MSP Mandal's Arts, Science and Commerce College, Kille-Dharur 413606 Maharashtra, India, ${ }^{2 *}$ Department of \\ Chemistry, S. M. Dnyandeo Mohekar College, Kallam, 413507 Maharashtra, India \\ Email: sureshvedpathak@gmail.com \\ Received: 18 Jan 2020, Revised and Accepted: 22 Mar 2020
}

\begin{abstract}
Objective: To report the ultrasound-assisted synthesis of some bioactive 2-furan-2-yl-4H-chromen-4-one derivatives

Methods: Oxidative cyclization of chalcones using iodine in dimethyl sulfoxide for the synthesis.
\end{abstract}

Results: Some bioactive 2-furan-2-yl-4H-chromen-4-one derivatives were synthesized from corresponding chalcones in the presence of iodine in dimethyl sulfoxide under ultrasound irradiation at ambient reaction conditions.

Conclusion: The use of ultrasound irradiation gave the advantages of higher yields, lower reaction time and simplicity compared to conventional methods for the synthesis of 2-furan-2-yl-4H-chromen-4-one derivatives.

Keywords: Chromen-4-one, Chalcones, Iodine, Ultrasound irradiation

(C) 2020 The Authors. Published by Innovare Academic Sciences Pvt Ltd. This is an open access article under the CC BY license (http://creativecommons.org/licenses/by/4.0/) DOI: http://dx.doi.org/10.22159/ijcpr.2020v12i3.38312. Journal homepage: https://innovareacademics.in/journals/index.php/ijcpr

\section{INTRODUCTION}

Ultrasound-assisted organic synthesis is another "Green" method used in many organic synthetic pathways for high efficiency, low waste, and low energy requirements. With high-intensity sound or ultrasound, radiation produces acoustic cavities, which can create extreme physical and chemical conditions in the cold fluid. The driving force for such synthesis has many benefits to clean and safe technologies for the environment, which reduces the production of source waste with better yields and selection, thereby increasing the recovery and quality of the product for crystallization and product recovery and refining processes. Sonication allows the use of non-activated and crude reagents as well as an aqueous solvent system; therefore it is friendly and non-toxic. Ultrasound is widely use for improving the traditional reactions that use expensive reagents, strongly acidic conditions, long reaction times, high temperatures, unsatisfactory yields and incompatibility with other functional groups [1]. In this context, the use of ultrasound to accelerate reactions has proven to be a particularly important tool for meeting the Green Chemistry goals of minimization of waste and reduction of energy requirements [2].

Chromones and chromen-4-ones, benzoannelated $\gamma$-pyrone [3, 4], are considered as privileged structures [5] widely distributed in nature known for their potential pharmacological activities [6-9]. An efficient synthetic route has been reported for the synthesis of 2-alkyl-substituted chroman-4-ones [10]. The incorporation of various functional groups to present highly substituted structures have successfully carried via distinct PD-mediated cross-coupling reactions [11, 12], Mannich reactions [13], and a $\mathrm{SmI}_{2}$-KHMDS-mediated Reformatsky type reaction [14]. Recently, some substituted chromone and chroman-4-one derivatives have been reported as potent and highly selective SIRT2 inhibitors [15]. As part of our ongoing research in the field of green chemistry directed synthesis, we herein wish to report a straightforward and conveniently efficient alternative protocol for the synthesis of diversely functionalized furan substituted chromen-4-ones from chalcones under ultrasound irradiation.

\section{MATERIALS AND METHODS}

Commercially available AR grade chemicals were used for synthesis. ${ }^{1} \mathrm{H}$ NMR and ${ }^{13} \mathrm{C}$ NMR spectra were recorded on $400 \mathrm{MHz}$ Varian Mercury plus $400 \mathrm{MHz}$ FT NMR spectrometer in $\mathrm{CDCl}_{3}$ using signals for residual protons and carbon atoms of the solvent as the references. Melting points were determined on the melting point apparatus (Model MP-96) and were not corrected. The progress of the reaction and purity of the product was monitored by TLC on Merck Silica gel 60 F254 UV-254 plates.

General procedure for the synthesis of chalcones

Chalcones were prepared by method reported in literature [16]. To a solution of substituted 2-hydroxyacetophenone ( $0.1 \mathrm{~mol})$ in ethanol (15 $\mathrm{ml})$, substituted heterocyclic aldehyde $(0.1 \mathrm{~mol})$ was added. To this mixture aqueous potassium hydroxide $(60 \%)$ was poured gradually with constant stirring and continues the stirring for $1.5 \mathrm{~h}$. After complete addition, the reaction mixture was kept for 14-16 $\mathrm{h}$ at room temperature. The potassium salt of chalcone was separated by ice-cold $10 \%$ hydrochloric acid $(20 \mathrm{ml})$. The separated solid was filtered and washed with ice-cold water $(2 \times 30 \mathrm{ml})$ till the washing was neutral to litmus. Recrystallized the compound with ethanol and dried at room temperature.

General procedure for the synthesis of 2-furan-2-yl-4Hchromen-4-ones

To a solution of chalcone $(0.01 \mathrm{~mol})$ in $20 \mathrm{ml}$ dimethyl sulfoxide, catalytic quantity of iodine was added. The mixture was then placed in an ultrasonic bath for the periods shown in table 1 , at $20-25{ }^{\circ} \mathrm{C}$. The progress of the reaction was monitored by TLC. After completion of the reaction, the reaction mixture was poured on icecold water; the separated solid was filtered washed with cold water followed by a dilute sodium-thiosulphate solution. The product was crystallized from ethanol.

\section{RESULTS AND DISCUSSION}

The intermediate, chalcones were synthesized by reacting equimolar amounts of furfuraldehyde with different 2-hydroxyacetophenones in the presence of $10 \%$ potassium hydroxide in ethanol by ClaisenSchmidt condensation. The cyclization of chalcones was then achieved by using catalytic amount of iodine in dimethyl sulfoxide under ultrasound irradiation (Scheme 1). The starting materials 3a-g on ultrasound irradiation afforded compounds $4 \mathrm{a}-\mathrm{g}$ within a few minutes in better yields than the conventional method (table 1). The use of ultrasound irradiation gave the advantages of higher yields, lower reaction time and simplicity compared to conventional methods. 


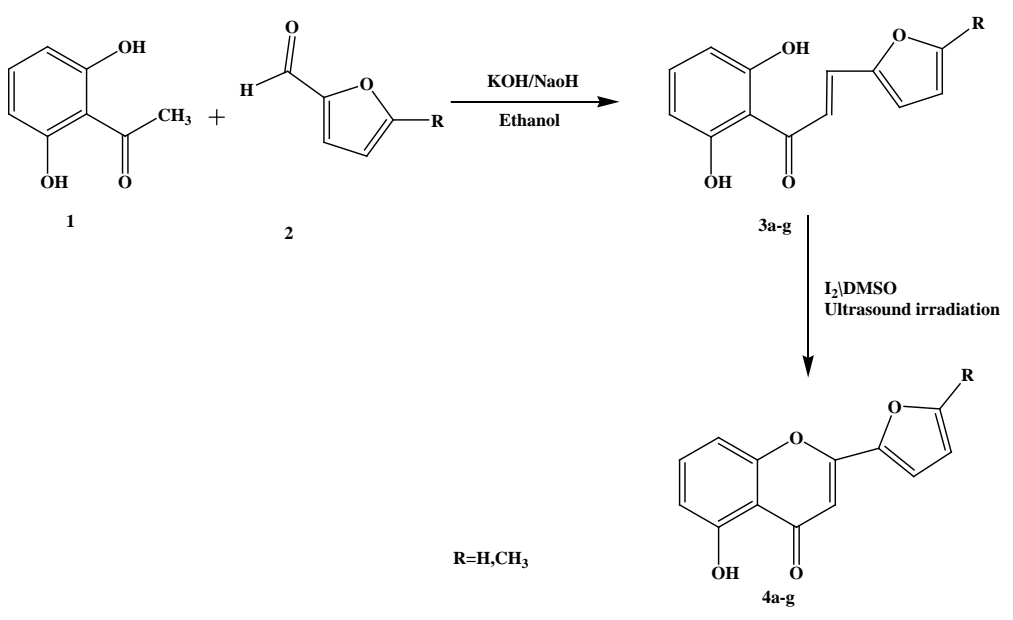

Scheme 1: Synthesis of 2-(5-substituted-furan-2-yl)-4H-chromen-4-ones

Table 1: Properties of compounds 4a-g

\begin{tabular}{|c|c|c|c|c|c|c|}
\hline Entry & Structure & Reaction time (min) & Color & $\begin{array}{l}\text { Molecular } \\
\text { weight }\end{array}$ & M. $\mathbf{P}^{\circ} \mathbf{C}$ & $\begin{array}{l}\text { Yield } \\
\%\end{array}$ \\
\hline $4 a$ & & 30 & Yellowish-brown & 242 & $219-220$ & 82 \\
\hline $4 \mathrm{~b}$ & & 45 & Coffee brown & 228 & $271-272$ & 73 \\
\hline $4 \mathrm{c}$ & & 50 & Pale yellow & 245 & $274-275$ & 70 \\
\hline $4 d$ & & 35 & White & 272 & $179-180$ & 82 \\
\hline $4 e$ & & 40 & White & 272 & $115-116$ & 77 \\
\hline $4 \mathrm{f}$ & & 55 & $\begin{array}{l}\text { Off } \\
\text { white }\end{array}$ & 247 & $143-144$ & 78 \\
\hline $4 \mathrm{~g}$ & & 70 & White & 281 & $192-193$ & 69 \\
\hline
\end{tabular}

All the compounds were characterized by using IR, and ${ }^{1} \mathrm{H}$ NMR data Generally, the flavones and flavonols exhibit absorption in 320-380 $\mathrm{nm}$ regions and $240-270 \mathrm{~nm}$ regions [17]. Compound 4a showed two absorption bands in the range of $339 \mathrm{~nm}$ for carbonyl group and 258 $\mathrm{nm}$ for hydroxyl group. The IR spectra of 4 a revealed broad band for $\alpha$, $\beta$-carbonyl group absorption at $\nu_{\max } 1691 \mathrm{~cm}^{-1}$ and a broad band at $1097 \mathrm{~cm}^{-1}$ due to the presence of ether linkage (C-O-C). ${ }^{1} \mathrm{H}$ NMR spectra of 4 a revealed chemo selectivity of the cyclo condensation. The presence of a singlet at 6.71 reveals the presence of pyrone ring. All the $\delta$ values of protons are in accordance with the reported values.

${ }^{13} \mathrm{C}$ NMR spectrum of compound $4 \mathrm{a}$ revealed fourteen distinctive carbon signals at $\delta \mathrm{C} 14.1,109.3,110.1,110.4,110.9,112.3,113.2$,
$136.9,145.2,154.7,158.3,162.2,168.6,181.9$. Finally, in the mass spectrum, molecular ion peak is observed at $\mathrm{m} / \mathrm{z} 242\left[\mathrm{M}^{+}\right], 243$ $\left[\mathrm{M}^{+}+1\right]$ and $244\left[\mathrm{M}^{+}+2\right]$ confirms the structure of the compound $4 \mathrm{a}$. The compound $4 \mathrm{~b}-\mathrm{g}$ are the same as obtained by the reported conventional procedure. The spectral analysis of these compounds is in accordance with the reported values $[17,18]$.

\section{CONCLUSION}

A general and green method has been developed for the synthesis of 2 (5-substituted-furan-2-yl)-4H-chromen-4-ones from furan substituted chalcones in dimethyl sulfoxide in the presence of iodine as catalyst under ultrasound irradiation at ambient conditions. The use of 
ultrasound irradiation gave the advantages of higher yields, lower reaction time and simplicity compared to conventional methods.

\section{FUNDING}

Dr. Babasaheb Ambedkar Marathwada University Aurangabad

\section{AUTHORS CONTRIBUTIONS}

Both the authors have contributed equally.

\section{CONCLUSION OF INTERESTS}

The authors confirm that this article content has no conflict of interest.

\section{REFERENCES}

1. Puri S, Kaur B, Parmar A, Kumar H. Applications of ultrasound in organic synthesis-a green approach. Curr Org Chem 2013; 17:1790-828.

2. Cintas P, Luche JL. Green chemistry: the sonochemical approach. Green Chem 1999;1:115-25.

3. Saengchantara ST, Wallace TW. Chromanols, chromanones, and chromones. Nat Prod Rep 1986;3:465-75.

4. Cottiglia F, Dhanapal B, Sticher 0, Heilmann J. New chromanone acids with antibacterial activity from Calophyllum brasiliense. J Nat Prod 2004;67:537-41.

5. Horton DA, Bourne GT, Smythe ML. The combinatorial synthesis of bicyclic privileged structures or privileged substructures. Chem Rev 2003;103:893-930.

6. Bhat AS, Whetstone JL, Brueggemeier RW. Novel synthetic routes suitable for constructing benzopyrone combinatorial libraries. Tetrahedron Lett 1999;40:2469-72.

7. Bauvois B, Puiffe ML, Bongui JB, Paillat S, Monneret C, Dauzonne D. Synthesis and biological evaluation of novel flavones-8-acetic acid derivatives as reversible inhibitors of aminopeptidase N/CD13. J Med Chem 2003;46:3900-13.
8. Kim HP, Son KH, Chang HW, Kang SS. Anti-inflammatory plant flavonoids and cellular action mechanisms. J Pharmacol Sci 2004;96:229-45

9. Gaspar A, Matos MJ, Garrido J, Uriarte E, Borges F. Chromone: a valid scaffold in medicinal chemistry. Chem Rev 2014;114:4960-92.

10. Friden Saxin M, Pemberton N, Andersson KD, Dyrager C, Friberg A, Grotli M, et al. Synthesis of 2-alkylsubstituted chromone derivatives using microwave irradiation. J Org Chem 2009;74:2755-9.

11. Dahlen K, Wallen EAA, Grotli M, Luthman K. Synthesis of 2,3,6,8-tetrasubstituted chromone scaffolds. J Org Chem 2006;71:6863-71.

12. Dahlen K, Grotli M, Luthman K. A scaffold approach to 3,6,8trisubstituted flavones. Synth Lett 2006;6:897-900.

13. Wallen EAA, Dahlen K, Grotli M, Luthman K, Synthesis of 3aminomethyl-2-aryl-8-bromo-6-chlorochromones. Org Lett 2007;9:389-91.

14. Ankner T, Friden Saxin M, Pemberton N, Seifert T, Grotli M, Luthman $\mathrm{K}$, et al. KHMDS enhanced $\mathrm{SmI}_{2}$-mediated reformatsky type $\alpha$-cyanation. Org Lett 2010;12:2210-3.

15. Friden Saxin M, Seifert T, Landergren MR, Suuronen T, Lahtela Kakkonen M, Jarho EM, et al. Synthesis and evaluation of substituted chroman-4-one and chromone derivatives as sirtuin 2-selective inhibitors. J Med Chem 2012;55:7104-13.

16. Sylvie, Richard DF, John H, Alex K, Nicholas JL. Potent antimitotic and cell growth inhibitory properties of substituted chalcones. Bioorg Med Chem Lett 1998;8:1051-6.

17. Shastri RA. Synthesis and antimicrobial activity of some novel pyrazoline and flavones derivatives derived from furan chalcone. World J Pharm Res 2015;4:642-51.

18. Khandapu BK, Mutchu BR, Thripuram VD, Polam N, Anandam $\mathrm{R}$, Navudu R, et al. Reaction of O-methylated flavones with semicarbazide: serendipitous selective demethylation. Org Commun 2018;11:116-22. 